\title{
Basic Doctrines of Buddhism and Modern Science
}

\author{
Dr. Daisuke Ueda \\ Prof. of Chūō Univ., Tokyo
}

1. Introductory Remarks. Buddhist philosophy is a system of religious metaphysics, whereas modern science is a positive and non-religious inquiry of nature. So that, needless to say, the two have two distinct characteristics. Yet, despite this, the standpoint of Buddhist philosophy is characteristically empirical and demonstrative, and its fundamental doctrines (originated by Buddhism and peculiar to it) are experimental (or we may say scientific). Hereby, a very close affinity can be observed in the realm of the scientific between Buddhism and science. In the following a few observations will be made regarding this point.

As we all are familiar with, it can be said that philosophies deriving from India are almost all systems of religious metaphysics. However, among them, Buddhism alone deviated from the rule, and being possessed of the experiential spirit, developed highly into a philosophy of experience in the history of philosophy. This fact can readily be seen with respect to Original Buddhism and, in particular, it becomes all the more clear in Zen which has developed most highly in the realm of the demonstrative and experiential in the history of Buddhism.

Since Buddhist philosophy and modern science are both characteristically empirical and demonstrative in their foundations and methods, it is only natural to think that their inquiry into truths must, in general, be concordant or harmonious. In other words, some of the truths discovered by modern science may possibly have already been in the possession of Buddhism, since it took the empirical approach from a very early period. Moreover, because of the fact that it resorted to a more thoroughgoing 
empiricism, it may be possible that some of the yet unanswered problems of modern science might have already either rightly or nearly been solved by Buddhist philosophy (for example, such problem as the relation between mind and body). And it may also be possible that the various new problems, such as freedom, which have arisen out of the advances made in modern science may, some day, seek the aid of Buddhist empirical philosophy.

On the other side, while Buddhism as a philosophy attempts to grasp reality as a whole without the use of hypotheses, modern science, in the form of the special sciences, inquires into the special aspects of phenomena, and consequently, in the process cannot escape the use of hypotheses. These differences in approach necessarily give birth to diverse views. In the following, some aspects of concordance of Buddhist philosophy and modern science, and some aspects of difference of the two, will be observed briefly.

\section{Empirical Character of Original Buddhism and Zen.}

Perhaps it is needless to point out here that the spirit of, and the attitude and method taken by the founder of Buddhism in seeking after the truths, were empirical, practical, and demonstrative. It is what scholars of the East and the West alike equally observe and praise, as "modern". And for him the experience or experienced world was all, sabbā. And it has also been exposed that Buddha's treatment of phenomena or experience, method of observation, reasoning, etc., are all scientific.

What then were Buddha's teachings? Naturally, they included some metaphysically dogmatic and non-empirical elements relating to the traditional teachings of karma and samsāra. However, it can clearly be seen that the original teachings of Buddhism, namely, teachings which are truly peculiar to Buddhism and which reflects upon the originality of the Buddha himself, are justly empirical and scientific. As we all know, the essential teachings of Buddhism are summarized in the Four Noble Truths, Twelvedivisioned Dependent Origination, and Three Cardinal Principles; and there, neither the Truths nor the Principles consist of any dogmatic or nonempirical elements. They have all been taught as empirical and demonstrative 
truths. And regarding the Twelve-divisioned Dependent Origination, there is general acceptance to the fact that it is not so much expounded for the sake of constructing a metaphysics of karma or samsāra as to demonstrate the empirical truths of dependent origination themselves.

Now the Twelve-divisioned Dependent Origination has great importance as a starting point of Buddhism, and manifests the meaning of paticcasamuppāda ("causal genesis"), which makes the base of all Buddhist doctrines. The paticca-samuppāda was to serve as an attack against the untruths of the monistic Brahma-Ātma theory and transformation theory (parināmavāda) of classical thought, and the pluralistic aggregation theory (ārambhavāda) of popular thought of the time, and, in turn, to show from the standpoint of empiricism, the truths of mutual dependence and conditionedness of all things and events, and as a consequence, to reveal non-substantiality (suññāā) of things. In addition, the Dependent Origination was introduced to counter determinisum (pubba kata hetu), casualism (ahetu apaccaya), and divine will (issara-nimmāna hetu), which were popular at the time. This matter also demands our deep consideration in discerning the relationship between Buddhism and modern science. For, science fixes nature and tends to be deterministic while taking the empirical approach; whereas, Buddhism asserts the opposite, i. e. denies determinism while assuming the same approach.

Now in paticca-samuppäda there are two meanings implied; namely, (1) the mutual relationship or conditionedness of all things, and (2) the act of originating or coming into existence (uppāda). The latter also carrsies the meaning of vanishing (nirodhā). Therefore, in looking upon the concept of paticca-samuppāda, the notions of arising and vanishing must also be a matter of great importance. Buddhism has countered the idee fixe of Brahma-Ātma theory, aggregation theory, and determinism, by the cognition that our experience of phenomena actually consists in such origination and extinction. In particular, the Impermanence (aniccā) in the Three Cardinal Principles can be looked upon as expressing the above fact of origination and extinction; and the Nirodhā in the Four Noble Truths and 
Nirvāṇa (Nirupadhiśeșa-nirvānaa) are possible only on this ground. Consequ. ently, it is incorrect to interpret pațicca-samuppãda solely in terms of mutual relationship (as, for instance, Max Walleser does). Moreover, the interpretation of the Mahāyāna Buddhism which relates paticca-samuppāda with the mutual relationship does not seem to do full justice to its original meaning. But, with Zen, which has been the most faithful in keeping with the empiricism of Original Buddhism, and developed it more fully, the notions of arising and vanishing have been fully apprehended as such, and thereby a new concept of Non-being, which is to be distinguished from suñnatā, has been established. Namely, in Zen uppãda has been understood as origination or coming-to-be from non-being ( $e x$ nihilo), nirodhā as vanishing or passing-away into non-being (in nihilum reverti); and in Zen this Non-being has been taught emphatically, as one of the most important doctrines of it.

Together with the Dependent Origination the five skandhas are taught. The skandhas are elementary data of immediate experience. They originate and vanish because of paticca-samuppāda; they have no constancy.

Out of the experimental truths mentioned above, several metaphysical conceptions, such as uncreated dharmas, Dharma, Nirvāna, etc., have been derived in early Buddhism. They were necessary inductions through the facts of experience, and therefore, are to be clearly distinguished in nature from the dogmatic suppositions of speculative philosophy. Although later Mahāyāna Buddhism hypothesized many metaphysical realities transcendent of experience and therefore non-experiential, Original Buddhism has never entertained any non-empirical metaphysical realities, excepting the traditional conceptions of karma and samsāra, which it dogmatically accepted. And Zen has faithfully observed the empirical approach of Original Buddhism, and developed it highly into the most advanced empirical philosophic system in Buddhist philosophy.

\section{Some Aspects of Modern Science Concurrent with Buddhist} Philosophy. It is only natural to conclude that there are mutually harmonious points in modern science and Buddhist philosophy because of 
the same empirical background. With respect to it, the following observations may be made: (1) Analytical observation of phenomena; reduction to simpler terms. (2) Cognition of inter-relatedness or relativity of things. This point is being increasingly stressed by modern science. (3) Cognition of the "Oneness of body and mind." This is represented in science as the psychophysical parallelism and interaction. (4) Idealistic or positivistic tendency. Physics, which can be considered the most representative of the physical sciences, essentially bases its foundations on the "sense-data" found in our immediate experience, and arranges them through our thoughts (or Kant's a priori) for its systematization; the various physical realities such as, elementary particles, waves, etc., are only convenient conceptual constructs for the arrangement of the "sense-data". (5) Denial of substance. Physical substance is denied, because the "sense-data" have become the basis for a physics; and the substantiality of physical realities such as, elementary particles, waves, etc., is also denied, because of their transformability. It is needless to say that psychology cannot conceive of a mental substance. (6) Cognition of impermanence. It needs not be said that the impermanence of the mind and its states is recognized in psychology, and this is also true in physics where the phenomena are treated as relatively constant. (Physics recognizes the transmutation of elements and the instability of elementary particles.)

\section{Some Aspects of Difference in Modern Science and Buddhist} Philosophy. Standing on the same empirical standpoint, it seems that the two ultimately would have to concur into a consistent system, but at the present stage, there are some points of difference observed between them. This seems to come mainly from the fact that the sciences are special inquiries into the particular aspects of phenomena and as a result they cannot avoid the use of hypotheses, while Buddhism does not use hypotheses and aims to attain the first cause or ultimate ground of the phenomena. Among the points of difference, the following seem to be the most important.

(1) View on causality. Buddhist philosophy searches ultimate cause or 
a "cause of the phenomena" (to use Kantian words), and even considers a moral causality from the metaphysical standpoint; but unlike science, it does not go minutely into the various causal relationships in the phenomena, namely, into the "cause in the phenomenon." On the contrary, modern science avoids the consideration of a metaphysical "cause of the phenomena," and concentrates on the inquiry into "cause in the phenom. enon" (arranging phenomena in concomitant relationship or temporal order). It searches laws or causalities only in a given steady state of phenomena, or in a "stereotyped memory of the process," to use Bergson's terminology. As a consequence, the real originating (ex nihilo) and the real vanishing (in nihilum) are not accounted for, and thence science necessarily tends to be deterministic. In actuality, however, the steady state of phenomena or "stereotyped memory" is only a case of experience or phenomena. Our world of experience does not stay constant; it is incessantly changing. And the changes involve a continual originating and vanishing, in part or in whole, and things, physical as well as mental, "come to pass" or "pass away". Accordingly, if science be really true to experience, it would have to recognize the constant disturbance or interruption of cause-effect sequence by virtue of such originating and vanishing. In other words, science has to admit that, besides natural causality, i. e. causality according to the laws of nature, there is contingency as well (of course with conditions attached). Paticca-samuppäda includes the meaning of conditioned contingency. (To-day in practice science studies the conditioned contingency, for instance such phenomena as an origination of mental states because of preceding physical states, but in theory, it does not correctly cognize the contingency as such, and supposes it as natural causality.)

Moreover, the things in the world of experience are all mutually related and interacting with one another, and besides, the world itself is heterogeneous and manifold; so that there is to be found a variety of causal relationships intermixed in a complicated manner. Each special science seeks specific causal relationships out of the world of experience 
by a "selective" process on the basis of setting up its specific methodological assumptions and conditions. In such a fashion, a variety of causalities, such as, mechanical, biological, psychological, psycho-physical, historical, etc. are found. Each of these causalities or laws is valid and cogent in the domain of each special science respectively, which has found it. But it is impossible in the actual world, which is always complexly changing, to see the methodologically specified conditions of phenomena remaining constant, which the special sciences deal with; any kind of phenomena cannot be "isolated" and kept constant. Accordingly, no causal-sequence which is based on the principles of the special sciences can continue uniformly; it is constantly disturbed or interrupted by other conditions of phenomena, mechanical series of cause and effect in physics making no exception. (Moreover, in Buddhism there is a situation which transcends the laws of causality, namely Nirvāna.)

(2) The place of man in Nature. Science treats man as one of the small existences in Nature; whereas, Buddhism includes nature in man's mind and lets hers be one with it because of the doctrine: "One mind is (at once) all things, all things are (at once) one mind." And on the question of the origin of man, science says man is a natural product of Nature; whereas, Buddhism, particularly Zen, says that "I came not from men nor the heavens," because of the standpoint of "non-being."

(3) Fixation view of Nature. Science fixes Nature without knowing "non-being". It denies the conceptions of origination and extinction because of its stand on ex nihilo nihil. And in turn, it introduces the conception of "becoming", which means the transformation from one state of being into another. However, therein the idea of ex nihilo nihil in itself is essentially only a supposition and not a fact of immediate experience. Buddhism also sets up the same supposition ex nihilo nihil. But it does this on the standpoint of true empiricism, cognizing the fact of origination and extinction. So that it necessarily creates the concept of substantial non-being, in other words, reality or being in the form of non-being.

Moreover, in Zen, Nature as a whole vanishes and originates ceaselessly. 